\title{
Educação financeira: programa de educação financeira nas escolas à luz da governamentalidade ${ }^{1}$
}

\author{
Noelle Cristina Alves Cabral* \\ Luciana Aparecida Silva de Azeredo** \\ Guilherme Muniz Pereira Chaves Urias***
}

\begin{abstract}
Resumo
Este trabalho objetiva analisar, à luz do conceito de governamentalidade foucaultiano, o livro Educação Financeira nas Escolas - Ensino Médio - Bloco 3. Fez-se uma pesquisa bibliográfica sobre consumo consciente, educação financeira, governamentalidade e consciência financeira para fundamentar a análise das situações didáticas do livro. Como resultado, observou-se que há contradição no material Bloco 3 no que tange ao consumo consciente, o que também não condiz com os objetivos do programa, de incentivar a cultura do planejamento, prevenção, investimento e consumo consciente. A análise aponta para a presença de técnicas de governamentalidade neoliberais que incitam os sujeitos a consumir de forma "consciente".

Palavras-chave: Educação financeira; Governamentalidade; Finanças.
\end{abstract}

Financial education: program of financial education in schools in the light of governmentality

\begin{abstract}
This work aims at analyzing, in the light of Foucault's concept of governmentality, the Financial Education School Book - High School - Block 3. A bibliographical research was done, emphasizing conscious consumption, financial education, governmentality and financial awareness, basis for the analysis of the didactic situations. As a result, a contradiction in the Block 3 material regarding conscious consumption was found, which does not fit the objectives of the program, which are to encourage the culture of planning, prevention, investment and conscious consumption. The analysis points to the presence of neoliberal governmentality techniques that encourage the subjects to consume "consciously".

Keywords: Financial education; Governmentality; Finances.
\end{abstract}

\section{Introdução}

Em uma entrevista aos jornalistas Ana Paula Ragazzi e Diogo Martins do jornalonline Valor Econômico, a especialista em educação financeira, Annamaria Lusardi, comentou sobre o analfabetismo financeiro, o qual é muito alto entre jovens e adultos. Como forma de redução dessa deficiência, ela ressalta, em sua entrevista, a importância de os países elaborarem programas para desenvolver este conhecimento entre os mais jovens, "os países deveriam apostar mais na educação financeira como forma de redução da desigualdade social" (MARTINS; RAGAZZI, 2014). E ainda afirma que "é importante focar nos jovens, propor regulações voltadas para esse público. São os jovens que as autarquias vão encarar no futuro" (MARTINS; RAGAZZI, 2014).

Pesquisas apontam que, de cada 10 (dez) pessoas entrevistadas, apenas 8 (oito) possuem nenhum ou poucoconhecimento sobre como fazer o controle das despesas pessoais. (SPC-BRASIL,
2017). Como apresentado por Bauman (2010) em "Vida a crédito", as consequências vivenciadas hoje por todos brasileiros sãoresultados do modo e da cultura na qual a sociedade foi criada, incitando-nos a "correr para os empréstimos cada vez que temos um problema a resolver ou uma dificuldade a superar"(BAUMAN, 2010, p. 34).

Diante deste cenário, este artigo tem como objetivo conhecer a Estratégia Nacional de Educação Financeira (ENEF) implementada por meio do decreto n. 7.397 de 22 de dezembro de 2010, cujointuito é "promover a educação financeira e previdenciária e contribuir para o fortalecimento da cidadania, a eficiência e solidez do sistema financeiro nacional e a tomada de decisões conscientes por parte dos consumidores", tendo como base o contexto histórico brasileiro sobre educação financeira e consumo. Para análise da estratégia, optou-se por explorarapenas o material livro do Aluno Bloco 3 Ensino Médio, desenvolvido pelo Programa de Educação Financeira nas Escolas, com o objetivo principal de analisar presença de técnicas de

\footnotetext{
*Endereço eletrônico: noellecac@ hotmail.com

***Endereço eletrônico: luciana.azeredo@cefetmg.br

****Endereço eletrônico: guilherme.urias@gmail.com
} 
governamentalidade neoliberais no livro em questão.

Atentando-se ao objetivo desse trabalho, foi realizada uma leitura crítica do material com intuito de analisar todas as propostas feitas aos alunos e seu conteúdo programático. Vale ressaltar que os demais livros do programa não foram analisados neste artigo, portanto, não é possível afirmar se tais aspectos encontrados neste trabalho, são também abordados nos demais blocos 1 e 2 do ensino médio. A hipótese inicial é de que o livro do Aluno Bloco 3 - Ensino Médio, elaborado pelas instituições e autarquias financeiras com apoio do governo, é um material desenvolvido para formatar os indivíduos para o sistema capitalista, por meio das técnicas de governamentalidade e não um material de cunho humanístico que visa à formação de cidadãos críticos.

No que tange à organização do artigo, primeiramente, serão abordados o histórico daeducação financeira no Brasil, a Estratégia Nacional de Educação Financeira, Programa de Educação Financeira nas Escolas e o conceito de Governamentalidade. Na sequência, será apresentada a análisede alguns trechos do Livro do Aluno Bloco 3. Ao final, apresentam-se algumas considerações com base na confrontação da revisão de literatura realizada e das análises empreendidas.

\section{Breve histórico da educação financeira}

Atualmente, nos noticiários, temos nos deparado com assuntos referentes a reformas e novas políticas, como a Reforma da Previdência e Reforma Trabalhista, isso nos remete ao questionamento deste trabalho, que busca entender, por que real motivo, o governo está impondo estas mudanças e principalmente apoiando iniciativas de programas de educação financeira por meio da ENEF. As justificativas apresentadas pelo governo para tais medidas são o aumento da perspectiva de vida da população e a baixa natalidade atual.

Diante deste cenário, observa-se que o programa de educação financeira nas escolas, elaborado pelas instituições do mercado financeiro e previdenciário, tem sido desenvolvido com o real intuito de propagar o conhecimento em educação financeira voltado ao consumo, de forma a "melhorar"o consumo dos cidadãos, a longo prazo, de maneira quepossam consumir sempre para alimentar o sistema neoliberal.

Ao analisar o contexto histórico do Brasil e sua relação com o consumo e a consciência financeira, deparamo-nos com três momentos determinantes.

O primeiro momento ocorreu na década de 90, período logo após o término do regime militar (1964-1985), com altos índices de inflação, desestabilização da moeda nacional e com acesso restrito à educação financeira. Apenas as pessoas que já possuíam alguma forma de investimento tinham acesso a este tipo de conhecimento por meio de "dicas de investimentos" de especialistas financeiros.

Altos índices de inflação, associados à baixa bancarização, crédito escasso e pouco acesso à informação desenhavam um cenário em que o brasileiro médio não conseguia planejar sua vida financeira, nem a curto ou a longo prazo. (COSENZA; CALIFE, 2014, p. 1)

A implantação do Plano Real (1994), segundo momento impactante, estabilizou a economia, diminuindo a inflação e estabilizando a moeda. Nos anos seguintes, a partir de 1999, a educação financeira começa a ganhar força devido ao aumento de aberturas de contas em bancos (expansão da bancarização) e ao controle da inflação (COSENZA; CALIFE, 2014).

$O$ terceiro momento, determinante para conscientização da importância da educação financeira, foi o acesso ao crédito e sua expansão.

O aumento do crédito concedido à pessoa física com recursos livres passou de 6,1\% do PIB, em dezembro de 2002, para $14,9 \%$ do PIB em dezembro de 2010. Isso pode ser atribuído, em grande medida, ao advento do crédito consignado, à facilidade do acesso ao financiamento de veículos e à venda à vista por meio de cartão de crédito. (MORA, 2015, p. 21)

O cenário dos anos anteriores vivido pelos brasileiros mudou, e a possibilidade de sonhar com uma nova forma de consumo tornou-se possível. Porém, os mesmos fatores que permitiram este advento também se tornarampreocupantes, no que diz respeito ao comportamento individual com as finanças (COSENZA; CALIFE, 2014).

Sob estas novas condições, várias obras começaram a surgir no intuito de orientar, ensinar e ampliar o conhecimento financeiro da sociedade, como, por exemplo, "Pai rico pai pobre" de Robert T. Kiyosaki (1997); "Independência Financeira" de Robert T. Kiyosaki e Sharon L. Lechter (2001); "Seu futuro financeiro" de Louis Frankenberg( 2000); "Casais inteligentes enriquecem juntos" de Gustavo Cerbasi (2004) e "Os segredos da mente milionária" 
de T. HarvEker (2006). Porém,

apesar dessa abordagem também ter como ponto central a conquista da prosperidade como objetivo maior, o que testemunhamos na prática foi o alçamento do consumo financiado pelo crédito - ao invés do planejamento - como sinônimo de progresso, de inclusão e de sucesso na vida. (COSENZA; CALIFE, 2014, p. 3)

Nos anos seguintes, a sociedade brasileira passou por um período de fortes estímulos ao consumo. Com trabalho e renda garantidos para grande parte da população, tendo em vista os investimentos estrangeiros e nacionais no país e a ampliação do poder de compra da nova classe $\mathrm{C}$, o volume da circulação do dinheiro aumentou consideravelmente no Brasil, fruto das políticas de estímulo ao consumo que contribuíram para o estabelecimento de um cenário econômico fértil e estável, que permitiu a uma grande parcela da população o acesso ao crédito (COSENZA; CALIFE, 2014).

A grande circulação de dinheiro, que viabilizou um ambiente econômico estável, possibilitou o aumento da oferta de produtos e serviços financeiros, entre eles o crédito, ampliando o poder de consumo de grande parte da população, inclusive daqueles anteriormente excluídos do sistema financeiro. (BANCO CENTRAL DO BRASIL, 2013, p. 08)

Nesse sentido, é importante destacar que o acesso ao crédito e a estabilidade do emprego foram fatores essenciais para conduzir parte da população brasileira ao endividamento, o qual é diferente de inadimplência, relacionada ao índice de pessoas com contas atrasadas, mas que ainda querem honrar suas dívidas. No período de 2004 a 2013, o percentual de inadimplentes era da ordem de $19,43 \%$, conforme Pesquisa de Endividamento e Inadimplência do Consumidor (PEIC) (FECOMERCIO, 2013). No momento atual esse percentual teve um aumento considerável e o nível de endividamento das famílias brasileiras subiu muito. Segundo pesquisa do Portal Serasa Experian (2017), "o número de consumidores inadimplentes no país chegou a 61 milhões” e está associado ao aumento do desemprego e à recessão econômica.

Outro fator que contribuiu ao longo dos anospara o aumento da inadimplência foi a falta de consciência financeira, pois, enquanto políticas de incentivo ao crédito cresciam, outras políticas, como a educação financeira, não foram instituídas.
Segundo Annamaria Lusardi, autoridade mundial em finanças pessoais e diretora da Escola de Negócios da Universidade Georgetown, a educação financeira é muito importante para tomada de decisões certas e para a construção de um futuro melhor. Além disso, é necessária diante de tantos instrumentos financeiros, cartões de crédito e contas em banco, que não são algo simples com os quais temos que lidar no dia a dia (OLIVEIRA, 2017). O conhecimento em educação financeira pode despertar a consciência das pessoas para decisões de consumo sustentáveis e proporcionar o conhecimento para o desenvolvimento de uma relação equilibrada com finanças (AEF-BRASIL, 2017).

Como algo gerador de mudança comportamental, a educação financeira tende a formar cidadãos mais conscientes dos riscos e oportunidades financeiras, auxiliando-os a fazer melhores escolhas, o que contribui para formação de uma sociedade mais responsável (OCDE, 2016).

Muito além de promover o desenvolvimento econômico, melhores decisões financeiras $\mathrm{e}$ planejamento de vida, a educação financeira é também uma ferramenta para formar cidadãos melhores, com maior conhecimento, autonomia, consciência, responsabilidade socioambiental e poder de escolha sobre diversas situações da vida. A "educação financeira está muito ligada ao nosso comportamento geral e ao nosso modo de ser no mundo. Evitar desperdícios, por exemplo, não é uma atitude puramente financeira" (CONEF, 2013, p. 3).

\section{Estratégia nacional de educação financeira - ENEF}

Desde meados dos anos 90, o Brasil participa da Organização para a Cooperação e Desenvolvimento Econômico (OCDE), que se dedica à "pesquisa e estudos para o aperfeiçoamento das políticas públicas nas mais diversas áreas e à troca de experiências entre países membros e parceiros" (ITAMARATY, 2016).

Essa cooperação entre o país e a OCDE se intensificou a partir de 1999, quando o conselho da organização decidiu criar um programa direcionado ao país. Desde então, a participação do Brasil tem ampliado, sendo atualmente membro associado de sete órgãos da OCDE, o que permite participar regularmente dos trabalhos de diversos comitês, "como os Comitês de Agricultura, de Estatísticas, de Competição, de Política Científica e Tecnológica, de Investimentos, de Comércio, do GT sobre Práticas 
Empresariais responsáveis, entre outros" (ITAMARATY, 2016).

A estratégia do Governo brasileiro, conforme os Parâmetros Curriculares Nacionais (PCN), é trocar experiências sobre políticas e programas de sucesso instituídos em outros países afim de "recriar as bases para um crescimento sustentável da economia, com inclusão social e preservação do meio ambiente" (ITAMARATY, 2016), destacando-se, dentre as prioridades estabelecidas entre Brasil e OCDE, o aperfeiçoamento dos programas sociais e educacionais, uma vez que "as implicações sociais e econômicas a longo prazo do baixo índice de educação financeira de grande parte da população mundial têm levado os governos a criar políticas específicas especialmente a partir de 2008" (ENEF, 2017).

No Brasil, o decreto n. ${ }^{\circ} 7.397$ de 22 de dezembro de 2010, instituiu a Estratégia Nacional de Educação Financeira (ENEF), uma política de Estado de caráter permanente, que tem como objetivo "promover a educação financeira e previdenciária e contribuir para o fortalecimento da cidadania, a eficiência e solidez do sistema financeiro nacional e a tomada de decisões conscientes por parte dos consumidores" (BRASIL, 2010).

Este decreto originou-se de uma política pública voltada para educação financeira, desenvolvida pelo Comitê de Regulação e Fiscalização dos Mercados Financeiros, de Capitais, de Seguros, de Previdência e Capitalização (COREMEC), grupo de trabalho criado em 2007 para desenvolver e propor a estratégia.

A relevância da implementação da ENEF está na adequação do novo perfil da sociedade brasileira aos "fatores como a complexidade e variedade crescente de produtos financeiros, aumento da expectativa de vida, e mudanças na composição e distribuição de renda" (BANCO CENTRAL DO BRASIL, 2012, p. 4). Porém, apesar de sua relevância, a ENEF não é tão divulgada, o que nos leva a pensar que talvez este Decreto tenha sido implementado apenas para atender as exigências de órgãos internacionais, como a OCDE, ou seja, "para fazer bonito" ou "para inglês ver", sem efetividade na prática.

Mudar o comportamento da sociedade com relação a finanças é algo a longo prazo que requer políticas permanentes, avaliações, revisões periódicas e programas que gerem transformações efetivas. Para isso, foi instituído pelo ENEF, o Comitê Nacional de Educação Financeira (CONEF), para "estabelecer metas de planejamento, financiamento, execução, avaliação e revisão da ENEF" (BRASIL. Art. 4. ${ }^{\circ}$, inciso II, Decreto n. $^{\circ}$ 7.397, de 22 de dezembro de 2010).

Diante das várias ações que fazem parte da ENEF, destaca-se o Programa Educação Financeira nas Escolas, que faz parte do Programa Transversal da ENEF, ou seja, "ações que perpassam vários setores e transcendem os interesses de uma instituição específica" (CONEF, 2014).

\section{Programa de educação financeira nas escolas}

O Programa de Educação Financeira nas Escolas é coordenado pela AEF-Brasil, "uma instituição sem fins lucrativos, qualificada como OSCIP (organização da sociedade civil de interesse público), que tem como missão promover o desenvolvimento social e econômico por meio do fomento da Educação Financeira no Brasil" (AEF-BRASIL, 2017). O objetivo do programa é "contribuir para o desenvolvimento da cultura de planejamento, prevenção, poupança, investimento e consumo consciente" (AEF-BRASIL, 2017).

Atualmente, este programanãoé obrigatório na grade curricular do ensino fundamental e médio das escolas públicas. O material é disponibilizado gratuitamente para ser baixado nos sites relacionados com os projetos da Estratégia Nacional de Educação Financeira (ENEF). A aplicação do material de educação financeira nas escolasé livre, ou seja, os professores têm liberdade para desenvolver os temas conforme a necessidade da turma, utilizando o material completo ou apenas alguns temas. Vale mencionar que não há uma disciplina/professor designados para trabalhar tais conteúdos, havendo apenas sugestão de que devem ser trabalhados de forma interdisciplinar.

Com intuito de nortear o Programa Educação Financeira nas Escolas foi criado o documento "Orientações para Educação Financeira nas Escolas", produzido pelo Grupo de Trabalho do COREMEC (Comitê Nacional de Educação Financeira), com o apoio consultivo do Grupo de Apoio Pedagógico (GAP) composto por representantes dos setores educacional e financeiro e de instituições da sociedade civil, presidido pelo Ministério da Educação (MEC), A partir desse documento foram elaborados os materiais didáticos para o Ensino Médio e Ensino Fundamental.

O conteúdo de educação financeira para as escolas tem base em duas dimensões, a espacial e a temporal, e também está interligado a sete objetivos, 
sendo quatro relacionados à dimensão espacial e três, à dimensão temporal (AEF-BRASIL, 2017).

A dimensão espacial está relacionada às ações tomadas no nível individual até o mais amplo nível, como o global. Caracteriza-se por ações e seus impactos no contexto social e engloba os níveis individual, local, regional, nacional e global (COREMEC, 2009, p. 9).Os objetivos do programa, dentro da perspectiva dessa dimensão, são:

1. Formar para cidadania: "ser cidadão é ser responsável e ativo na sociedade, protagonizando a construção da democracia. [...] e a Educação Financeira tem como principal propósito ser um dos componentes dessa formação para a cidadania" (COREMEC, 2009, p. 10).

2. Ensinar a consumir e a poupar de modo ético, consciente e responsável: "oconsumo em níveis adequados é imprescindível para o bom funcionamento da economia, a questão é torná-lo uma prática ética, consciente e responsável, equilibrada com a poupança" (COREMEC, 2009, p. 11).

3. Oferecer conceitos e ferramentas para a tomada de decisão autônoma baseada em mudança de atitude:

Espera-se que os indivíduos e as sociedades tenham condições de moldar seu próprio destino de modo mais confiante e seguro e que deixem de ser beneficiários passivos de programas econômicos e sociais para se tornarem agentes de seu próprio desenvolvimento (COREMEC, 2009, p. 12)

Vale mencionar que os programas sociais podem ser necessários em situações extremas. Vale ainda salientar que este trabalho não tem como objetivo discutir as políticas públicas de assistência social, o sistema educacional brasileiro e o sistema de saúde pública, mas sim, analisar se a proposta do material didático em análise é atuar de forma humanística, papel da escola, a nosso ver, ou apenas por uma perspectiva neoliberal, utilizando-se de técnicas de governamentalidade para forma(ta)r os jovens a uma educação financeira direcionada para o consumo.

4. Formar disseminadores: "pretende colaborar para uma formação mais crítica de crianças e jovens que podem ajudar suas famílias na determinação de seus objetivos de vida, bem como dos meios mais adequados para alcançá-los" (COREMEC, 2009, p. 12).
Já a dimensão temporal está relacionada às consequências das decisões no tempo, passado, presente e futuro. As ações realizadas no presente têm impacto na situação futura, assim como as situações do futuro são consequências das decisões tomadas no presente. Os objetivos que se interligam a essa dimensão são:

1. Ensinar a planejar a curto, médio $e$ longo prazos: "a educação financeira intenciona conectar os distintos tempos, conferindo às ações do presente uma responsabilidade pelas consequências do futuro" (COREMEC, 2009, p. 13).

2. Desenvolver a cultura da prevenção: para garantir maior tranquilidade diante das situações há de se conhecer o leque de opções disponíveis, tais como evitar desperdícios, guardar dinheiro, fazer seguros diversos ou investimentos ou dispor de planos de previdência (pública ou privada). (COREMEC, 2009, p. 13)

3. Proporcionar possibilidade de mudança da condição atual:

os conhecimentos e competências oferecidos pela educação financeira ajudam a superar e evitar dificuldades econômicas mais graves, podendo auxiliar o indivíduo a rever suas atitudes e sair da condição de endividamento.(COREMEC, 2009, p. 14)

O material didático foi elaborado com essas propostas e objetivos, tomando por base os resultados das pesquisas do Instituto Data Popular (2008) que mostravam, na época, que, dentre as famílias brasileiras, 36\% tinham perfil "gastador", $54 \%$ não conseguiram honrar suas dívidas pelo menos uma vez na vida e apenas $31 \%$ poupavam regularmente para a aposentadoria (COREMEC, 2009, p. 1). Uma pesquisa mais recente realizada pelo SPC Brasil (2015) revelou que 7 (sete) em cada 10 (dez) pessoas sentem dificuldade para manter um controle de seu orçamento pessoal e, ainda, 4 (quatro) em cada 10 (dez) pessoas sentem-se seguras para gerenciar/organizar o próprio dinheiro. A respeito das fontes de conhecimento para gestão financeira, os resultados indicam que $48 \%$ o obtiveram em conversas com amigos e familiares; $46 \%$, em revistas, jornais e noticiários e 33\%, em sites e blogs especializados. Tais dados evidenciam que a deficiência em educação financeira ainda é 
perceptível no contexto social brasileiro.

O programa divide-se em dois níveis: Ensino Fundamental e Ensino Médio. Após o impacto positivo do programa piloto realizado com o Ensino Médio em 2010, iniciou-se a etapa piloto com o Ensino Fundamental em 2015. Países que já possuem programas de educação financeira indicam que os resultados são melhores quando a educação é iniciada mais cedo entre as crianças, porque estas iniciarão suas vidas aprendendo conteúdos e comportamentos financeiros para, pouco a pouco, começar a agir com consciência financeira, tendo comportamentos de autonomia e confiança para tomada de decisões. Ademais, elas se tornam multiplicadoras da ideia, partindo do pensamento individual para o impacto global.

A seguir, apresentam-se os conteúdos e a disposição dos materiais dos dois níveis de ensino e seus respectivos Livros conforme a série do aluno. Em detalhes, apresentam-se as temáticas, as quais são desenvolvidas em sala de aula pelos professores.

FIGURA 1: Livro Educação Financeira nas Escolas - Ensino Fundamental

\begin{tabular}{|c|c|c|c|c|}
\hline & \multicolumn{4}{|c|}{ Livro Educação Financeira nas Escolas - Ensino Fundamental } \\
\hline & Livros 1 ao 4 & Livros 5 e 6 & Livros 7 e 8 & Livro 9 \\
\hline \multirow[b]{5}{*}{ Temática } & Produção e consumo & \multirow{4}{*}{\multicolumn{2}{|c|}{$\begin{array}{c}\text { Estes livros foram desenvolvidos com uma abordagem lúdica, } \\
\text { que privilegia a participação ativa dos alunos. }\end{array}$}} & \multirow{4}{*}{$\begin{array}{l}\text { Este livro apresenta os conceitos simulando } \\
\text { o mundo virtual que encanta os alunos. }\end{array}$} \\
\hline & Organização & & & \\
\hline & Cuidados & & & \\
\hline & Planejamento & & & \\
\hline & $\begin{array}{l}\text { Cada ano os conteúdos sociais } \\
\text { são abordados de forma } \\
\text { diferenciada. }\end{array}$ & $\begin{array}{l}\text { Aventura solo } \\
\text { Pré-adolescência } \\
\text { O aluno aprende a tomar } \\
\text { decisões, com jogos que } \\
\text { decidem as ações do } \\
\text { personagem do livro. }\end{array}$ & \begin{tabular}{|c} 
Pervasivo \\
Mundo fantasia ao real \\
Livro contém situações sociais, \\
trabalho em grupo, educação \\
com entretenimento; sendo de \\
negociação, estratégia, \\
cooperação; o aluno aprende \\
conteúdos e comportamentos \\
financeiros.
\end{tabular} & $\begin{array}{l}\text { "Impressite" } \\
\text { Resumo de todos os conteúdos } \\
\text { Livro se assemelha a navegação em um } \\
\text { site; ideia de troca interespacial (público e } \\
\text { privado); acesso ao assunto completo de } \\
\text { forma simples e interessante. }\end{array}$ \\
\hline
\end{tabular}

CONEF: Comitê Nacional de Educação Financeira. Eđucação Financeira nas escolas 1 e 5, livro do professor. Brasilia: DF. CONEF, 2014

FIGURA 2: Livro Educação Financeira nas Escolas - Ensino Médio

\begin{tabular}{|c|c|c|c|}
\cline { 2 - 4 } \multicolumn{1}{c|}{} & \multicolumn{2}{c|}{ Livro Educação Financeira nas Escolas - Ensino Médio } \\
\cline { 2 - 4 } & Bloco 1 & Bloco 2 & Bloco 3 \\
\hline \multirow{4}{*}{ Temas } & $\begin{array}{c}\text { O que você já sabe? } \\
\text { Sonho Planejado }\end{array}$ & $\begin{array}{c}\text { O que você já sabe? } \\
\text { Sonho Planejado }\end{array}$ & $\begin{array}{c}\text { O que você já sabe? } \\
\text { Sonho Planejado }\end{array}$ \\
\cline { 2 - 4 } & Vida familiar cotidiana & Trabalho & Bens públicos \\
\cline { 2 - 4 } & Vida Social & Empreendedorismo & Economia do pais \\
\cline { 2 - 4 } & Bens Pessoais & Grandes Projetos & Economia do mundo \\
\cline { 2 - 4 } & &
\end{tabular}

CONEF: Comitê Nacional de Educação Financeira. Educação Financeira nas escolas: ensino médio. 1.ed. Brasilia: DF. CONEF, 2013

O material didático é dividido em duas versões, a do aluno e a do professor. Seu conteúdo está disponibilizado gratuitamente para download no site edufinanceiranaescola.gov.br. É possível baixar os livros completos ou por capítulos.

Vale mencionarque a ideia do Programa é também estimular a troca de experiências e conhecimentos entre os professores de todas as matérias,a fim de adequarem em quais aulas poderão incluir o tema "educação financeira", promovendo interdisciplinaridade, para que o aluno entenda que a educação financeira não é um tema isolado, mas presente em todos os âmbitos do diaadia.

\section{Programa de educação financeira nas escolas e governamentalidade}

O termo governamentalidade, cunhado pelo filósofo francês Michel Foucault (1926-1984), refere-se "ao esforço de criar sujeitos governáveis através de várias técnicas desenvolvidas de controle, normalização e moldagem das condutas das pessoas" 
(FIMYAR, 2009, p. 04), em outras palavras,

o conjunto constituído pelas instituições, procedimentos, análises e reflexões, cálculos e táticas que permitem exercer essa forma bastante específica e complexa de poder, que tem por alvo a população, como forma principal de saber a economia política e por instrumentos técnicos essenciais os dispositivos de segurança. (REVEL, 2005, p.54)

O conceito de governamentalidade se realiza por meio de técnicas neoliberais que condicionam as pessoas, na sua liberdade, a um determinado pensamento, que geralmente é sustentado por um grupo de interesse específico.

Governamentalidade não se trata de uma força dominante que exerce controle direto sobre a conduta de indivíduos, mas uma tentativa de determinar as condições nas quais, indivíduos são capazes de conduzir-se livremente. (HAMANN, 2012, p. 126 Apud ABREU, 2015, p. 49)

"Sempre que o governo anuncia um novo programa ou uma nova lei, o cidadão-eleitor que deseje analisar benefícios e custos dessa intervenção pode se perguntar: qual a falha de mercado que se está querendo corrigir?" (MENDES, 2011, p. 1). Define-se como falha de mercado, situações em que o mercado não é capaz de ofertar a quantidade necessária de algum bem ou serviço para a sociedade.

Associado ao assunto educação financeira, pode-se citar a negativa das instituições financeiras de liberarem o acesso ao crédito (serviço) a $64,17 \%$ dos brasileiros (KASTNER, 2017), devido ao alto nível de inadimplência, ocasionado pelo desemprego, pela recessão econômica e pelo baixo nível de conhecimento financeiro, objeto de nosso estudo.

Neste contexto, a educação financeira atua como um tipo de externalidade que pode ser positiva ou negativa. Segundo Mendes (2011, p. 4), a existência da externalidade causa a necessidade de intervenção do Estado,

porque na presença de elevadas externalidades, $\mathrm{o}$ elemento que a causa (indivíduo, família, firma, etc.) não está preocupado com o custo gerado pela externalidade negativa ou com o benefício gerado pela externalidade positiva. Ele toma suas decisões de produção e consumo pensando prioritariamente nos seus próprios custos e benefícios. (MENDES, 2011, p. 4)

O decreto que institui a ENEF é uma ferramenta do governo para reparar a externalidade negativa do analfabetismo financeiro e também uma técnica de governamentalidade. O Programa de Educação Financeira nas Escolas é uma das formas de ofertar uma externalidade positiva por meio da educação básica, com resultados a longo prazo,

ao instituir um campo de saber (neste caso saber financeiro), o poder se articula para que este gere práticas que logo se corporificarão como verdades, instituindo e modificando o comportamento dos indivíduos e da sociedade, conduzindo suas condutas para atingir determinados fins. (ABREU, 2015, p. 68)

Uma vez que o Programa foi elaborado por, dentre outros, agentes especializados em finanças, como BCB (Banco Central do Brasil), CVM (Comissão de Valores Mobiliários), PREVIC (Superintendência Nacional de Previdência Complementar), SUSEP (Superintendência de Seguros Privados), ou seja, por uma composição de agentes financeiros, ele tende a "legitimar um tipo de educação financeira que satisfaça aos interesses desses grupos" (FERNANDES, VILELA, 2016, p. 12).

Em um modelo econômico neoliberalista, o governo tende a eximir-se da responsabilidade assistencialista, gradativamente por meio de programas e decretos de interesse social. A Constituição Brasileira garante direitos ao cidadão, assim como ressalta o dever do Estado para com estes direitos, entre eles, o direito à educação e à saúde. Porém, o que se observa é uma alta arrecadação de impostos, que não é devidamente revertida à população, como notamos pela baixa qualidade dos serviços prestados pelo Estado. Dito de outro modo, "o Estado não está mais em jogo nas relações sociais, fica de fora e se torna garantidor de seu progresso" (GORDON, 1991, p. $34^{2}$ ). Em outras palavras,

a ENEF através da articulação de saberes e práticas pretende utilizar o sistema educacional para transferir à população grande parte da responsabilidade pela administração da economia nacional não só no Brasil, mas em todos os países que vem adotando esta política que cada vez mais assume um caráter transnacional. (ABREU, 2015, p. 52)

É importante observar a conjuntura do Programa, seus criadores e sua finalidade. $\mathrm{O}$ capitalismo sobrevive do mercado, que é movido pelo consumo, que se dá por meio daação de compra e vendade bens e serviços. Ensinar aos jovens educação financeira para torná-los protagonistas de 
suas vidas (responsáveis pelas suas decisões) pode estar relacionado a educá-los para uma consciência de consumo. Vale ressaltar que o"discurso consumista neoliberal tende a formatar os sujeitos do consumo, apostando neles para fazer a roda da economia girar" (ABREU, 2015, p. 26). Cabe ainda mencionar que, na apresentação do livro do Aluno Bloco 3 - Ensino Médio, é citado, dentre os objetivos do programa, o "desenvolver a cultura do consumo consciente" (CONEF, 2013).

Repara-se que o consumo se tornou o grande combustível da economia capitalista brasileira, impulsionando-a positiva e negativamente. "A questão não está em consumir menos e sim consumir melhor e de forma responsável para que se possa consumir sempre" (ABREU, 2015, p. 24). Os discursos relacionados àeducação financeira, ao consumo consciente e à autonomia dos indivíduos presentes no Livro do Aluno Bloco 3, são disfarces que visam ao assujeitamento da sociedade ao mercado capitalista, ou seja, objetivam "a condução eficaz da conduta dos outros para o alcance de certos fins" (CÁSTROGÓMEZ, 2010apud ABREU, 2015, p. 34).

Por meio da leitura realizada do material, observa-se que o programa, como "todo sistema de educação é uma maneira política de manter ou de modificar a apropriação dos discursos com saberes e os poderes que eles trazem consigo"(FOUCAULT, 1999apud ABREU, 2015, p. 66), ou seja, o Livro do Aluno - Bloco 3 - Ensino Médio do Programa de Educação Financeira nas Escolas e algumas das atividades nele propostas, "além de ocultarem a possibilidade de reação e de crítica, buscam construir indivíduos maleáveis e fáceis de governar" (FIMYAR, 2009, p. 43).

\section{Análise e resultados}

\section{Livro do aluno - bloco 3 - ensino médio}

O Programa de Educação Financeira nas Escolas, em especial para o Ensino Médio, segundo os órgãos governamentais, tem exatamente o objetivo de iniciar essa nova cultura de consciência por meio da educação básica,

o Programa foi desenvolvido para as escolas porque a instituição escolar é um espaço fundamental para construção das competências necessárias para o jovem enfrentar os desafios sociais e econômicos da sociedade, e também para a construção e o exercício da cidadania.(CONEF, 2013, p. 3)
O programa do Ensino Médio teve início como projeto piloto de agosto de 2010 até dezembro de 2011, em 900 escolas com 26.000 alunos, distribuídos nos estados de São Paulo, Rio de Janeiro, Ceará, Tocantins, Minas Gerais e no Distrito Federal. Conforme o documento de Resultados da Avaliação de Impacto do Projeto Piloto de Educação Financeira nas Escolas, descobriu-se que

o programa de educação financeira levou a melhorias significativas no conhecimento, nas atitudes e no comportamento financeiro dos alunos. Especificamente, nossos resultados indicam que o programa levou a maior proficiência, autonomia financeira e intenção de poupar; levou a poupança e comportamento de gastos aprimorados, assim como a maior participação dos alunos nas finanças domiciliares. (BM\&FBOVESPA, 2012, p. 3)

As informações obtidassão resultados de uma avaliação que utilizou um método de atribuição aleatória, única avaliação de um programa de educação financeira no mundo, que se dividiu em "grupo de tratamento" (que receberam o projeto) e o "grupo de controle", (que não o receberam) (BM\&FBOVESPA, 2012). A avaliação englobou 3 semestres letivos entre agosto de 2010 e dezembro de 2011 e, no início, aplicou-se uma avaliação diagnóstica para saber qual o nível de conhecimento dos alunos sobre educação financeira,

em seguida, em dezembro de 2010, a primeira avaliação somativa foi implementada, que permitiu que conhecêssemos os avanços preliminares dos 4 primeiros meses de projeto. Por fim, em dezembro de 2011, realizou-se a avaliação final do programa, após o término das atividades do projeto nas escolas. Os resultados que apresentamos aqui derivam desses 3 momentos da avaliação. (BM\&FBOVESPA, 2012, p. 2)

O material de educação financeira do ensino médio é composto por três livros, denominados "blocos". Optamos por abordar neste trabalho apenas o livro 3, que trata dos temas de Âmbito Social, como bens públicos, economia do país e economia do mundo. Essa escolha do livro 3 motivou-se pelo fato de que este simboliza o fechamento de um ciclo na vida do adolescente antes de partir para sua fase adulta mais independente, na qual terá mais protagonismo e precisará tomar decisões 
importantes. Cada livro é composto por diversas situações didáticas (SD), que se caracterizam por situações próximas do cotidiano. Estas SD estão distribuídas em três blocos:

FIGURA 3: Distribuição dos Livros do Ensino Médio

\begin{tabular}{|c|c|c|c|}
\cline { 2 - 4 } \multicolumn{1}{c|}{} & Bloco 1 & Bloco 2 & Bloco 3 \\
\hline \multirow{4}{*}{ Livros } & $\begin{array}{c}\text { Situações da Vida Pessoal } \\
\text { e Familiar no curto prazo: }\end{array}$ & $\begin{array}{c}\text { Situações da Vida } \\
\text { Pessoal e Familiar no } \\
\text { médio e longo prazo: }\end{array}$ & $\begin{array}{c}\text { Situações do Pais e do } \\
\text { Mundo em Articulação } \\
\text { com a sua vida Pessoal } \\
\text { e Familiar, no curto, } \\
\text { médio e longo prazo: }\end{array}$ \\
\hline \multirow{2}{*}{ Temas } & Vida Familiar Cotidiana & Trabalho & Bens Públicos \\
\cline { 2 - 5 } & Vida Social & Empreendedorismo & Economia do pais \\
\cline { 2 - 5 } & Bens Pessoais & Grandes Projetos & Economia do Mundo \\
\hline
\end{tabular}

Fonte: AEF-Brasil, 2017

Para cada SD, há uma proposta de ação ao aluno, ou seja, um convite para colocar em prática o assunto tratado na aula. Esta ação é chamada de "Experimente!". Há também, em todo material, ícones especiais que se organizam em Responsabilidade Social, Aluno Multiplicador e Tomada de Decisão Autônoma, que "destacam os principais aspectos desse programa e procuram deixar mais clara a mensagem de qual é o papel do aluno como cidadão em determinadas questões trazidas pelas SDs" (CONEF, 2013, p. 3). Abaixo, apresenta-se a estrutura do Livro do Aluno Bloco 3 Ensino médio, o qual é objeto de análise neste trabalho:

FIGURA4: Distribuição do Livro Blobo 3 do Ensino Médio

\begin{tabular}{|c|c|c|c|}
\hline & \multirow{2}{*}{\multicolumn{3}{|c|}{ Bloco 3}} \\
\hline & & & \\
\hline & \multicolumn{3}{|c|}{ Situações do Pais e do mundo em articulação com a sua vida pessoal e familiar, no curto, médio e longo prazos } \\
\hline SD (inicial) & \multicolumn{3}{|c|}{ O QUE VOCÊ JÁ SABE? } \\
\hline Tema & 7 - Bens Públicos & 8 - Economia do pais & 9 - Economia do mundo \\
\hline \multirow{7}{*}{ SDs } & Tudo tem o seu preço & Cultura e esportes & Fasciculo especial sobre moeda \\
\hline & Orçamento escolar & Meu bicho-papão nunca foi inflação & Rádio sul-americana \\
\hline & Livro escolar & $\begin{array}{c}\text { Supervisores do sistema financeiro } \\
\text { nacional }\end{array}$ & O jogo dos blocos econômicos \\
\hline & Espaço Público & Falando "economês" & Negócio da China \\
\hline & Serviços públicos & Mercado & Organismos internacionais \\
\hline & Corrupto eu? & Previdência & O bem-estar do seu pais \\
\hline & Rap do Contador & Salário Minimo & Momento de crise: e eu com isso? \\
\hline SD (final) & \multicolumn{3}{|c|}{ SONHO PLANEJADO } \\
\hline
\end{tabular}

A aplicação do material de educação financeira é livre. Os professores têm liberdade para desenvolver os temas conforme a necessidade da turma. Não é obrigatório seguir a ordem do livro, mas recomenda-se que as SD "O que se sabe?" (inicial) e "Sonho planejado" (final) devem abrir e fechar cada bloco respectivamente.

No material didático explorado, Livro Bloco 3 Aluno - Ensino Médio - Âmbito Social, ensina-se, entre outros temas, sobre economia no âmbito nacional e mundial; "economês" (linguajar típico da área econômica) e a função dos órgãos responsáveis pela fiscalização das instituições financeiras e previdenciárias.

\section{Livro do aluno - bloco 3 e as técnicas neoliberais de governamentalidade}

Atentando-se ao objetivo deste trabalho, foi feita uma leitura crítica do material escolhido com o 
intuitode analisar todas as propostas feitas aos alunos e seu conteúdo programático. Diante dessa leitura, observaram-se alguns trechoscontraditórios, que confirmaram nossa hipótese inicial da presença de técnicas de governamentalidade neoliberais no programa, e consequentemente, no material. Tais contradições presentes no material serão apresentadas a seguir em dois eixos: consumo "consciente" e isenção do Estado.

\section{Eixo 1 - consumo "consciente"}

Como exemplos da presença da contradição, cita-se a ideia exposta anteriormente de que o Programa de Educação Financeira na Escola esteja não só em busca de formar jovens cidadãos com consciência financeira, mas também com uma consciência de consumo, fato observável por frases como, "tomar decisões autônomas sobre consumo" (CONEF, 2013, p. 4); "contribuir para a eficiência e a solidez dos mercados financeiro, de capitais, de seguros, de previdência e de capitalização" (CONEF, 2013, p. 1) e também por situações hipotéticas, como no capítulo "Economia do país", no trecho de "Pergunte aos especialistas". A dúvida apresentada é sobre abrir o próprio negócio sem possuir dinheiro suficiente para tal. O especialista responde:

Todas as pessoas têm sonhos, projetos que desejam realizar, mas nem sempre têm o dinheiro necessário. Justamente para resolver esses problemas, facilitando a vida de poupadores (quem está com dinheiro disponível) e tomadores (quem está com dinheiro faltando), surgiu a atividade de intermediação financeira feita pelo mercado financeiro. Sugiro que você procure um banco de sua confiança ou uma cooperativa de crédito e se informe sobre as condições de financiamento no seu caso. (CONEF, 2013, p. 79)

Este trecho é relevante, pois inicia com "pessoas têm sonhos, projetos que desejam realizar", o que dá a ideia de generalização, ou seja, de não se limitar ao caso apresentado. Em seguida, discorre, com palavras "fáceis", que justamente para resolver o problema da falta de dinheiro existem os facilitadores (bancos, financeiras, entre outros). $\mathrm{O}$ texto não menciona outras alternativas, não explicita de forma clara e livre que existem outras opções, como a de poupar; emprestar dinheiro de um amigo ou escolher uma outra forma que poderá levá-lo a alcançar seus sonhos.Ademais, não se mencionam os riscos de um empréstimo, tampouco se questiona o retorno desse investimento. Há apenas a sugestão de "procure um banco de sua confiança ou uma cooperativa de crédito" para realizar um financiamento, o que nos remete ao grupo que fez parte da elaboração do material em questão. Neste trecho evidencia-se ainda a perspectiva neoliberal adotada pelos autores, em detrimento de uma postura humanística e social que condiz com o papel socialda escola, local este onde o programa é implantado.

No início do livro, na parte de Boas Vindas, os autores informam que durante o estudo do livro, os alunos irão aprender muitas coisas, dentre elas a "tomar decisões autônomas sobre o consumo, poupança e investimento" (CONEF, 2013, p. IV). Como forma de ressaltar essas mensagens principais do material, os autores distribuíram ao longo do texto três tipos de ícones especiais e, dentre estes, o de Tomada de Decisão Autônoma. Porém, ao longo da leitura do livro, encontram-se apenas dois ícones referentes à ação, ou seja, se um dos principais objetivos é proporcionar, por meio do aprendizado, autonomia, esta não foi prioritariamente ressaltada no material analisado, assim como poucas propostas foram expostas ao leitor para sua própria reflexão e escolha, como:

DÚVIDA: Fala, professor. Eu recebi uma grana de herança da minha avó e estou pensando em investir para no futuro ter o meu próprio negócio. Um amigo me falou de um clube de investimentos e outro de fundo de investimentos. Qual é a diferença entre os dois? Qual é o melhor? (Mateus, por e-mail). ESPECIALISTA: Estamos falando de duas alternativas diferentes para investir a sua herança e a poupança que você fizer daqui pra frente. A melhor opção para você será a mais adequada ao seu perfil de investidor e seus projetos de vida. Veja as características desses investimentos, mas não esqueça de que a escolha é sua! (CONEF, 2013, p. 86)

Como na dúvida hipotética, os autores parecem não direcionar a escolha, mas apenas mencionam as formas de investimentos, o clube e fundo de investimento, sem dar detalhes sobre ambos, seus prós e contras, ou seja, não houve uma dica real, nem foram oferecidos parâmetros para análise e decisão "conscientes". Vale ainda ressaltar o fato de a dúvida apresentada não fazer parte darealidade do alunado comumente encontrado na escola pública brasileira, a qual o Programa pretende atender. Em sua maioria, os alunos de escolas públicas têm situação financeira e social precária e moram em bairros periféricos, muitas vezes, sem acesso a bens culturais e materiais. 


\section{Eixo 2 - Isenção da responsabilidade do estado}

Com relação à outra vertente da análise, a desobrigação do estado,

os elaboradores de políticas podem, assim, restringir, e realmente restringem, o modo como pensamos sobre a educação em geral e sobre as políticas educacionais específicas, particularmente através da linguagem em que tais políticas são moldadas. O uso de repertórios discursivos tirados das áreas do comércio, marketing e finanças é uma das formas pelas quais isso é feito. (FIMYAR, 2009, p. 43)

Um trecho que reforça esta abordagem para com o leitor é o capítulo "Tudo tem o seu preço", na SD "Experimente!", que propõe reflexões e atividades aos alunos. Tal trecho aborda o custo por aluno do Ensino Médio para o Governo, custo que envolve livros, material escolar, uniformes, refeições, passagens de ônibus, entre outros.

As escolas particulares recebem as mensalidades para pagar suas despesas. Os alunos da rede pública não pagam mensalidade e, em vários casos, recebem livros e uniformes, além de ter suas passagens de ônibus subsidiadas pelo governo. Você já parou para pensar no custo de tudo isso? (CONEF, 2013, p. 15)

É abordado o tamanho da conta do governo com a escola pública, ressaltando que os alunos de escola pública "não pagam" mensalidade, como os das escolas particulares (CONEF, 2013). Além disso, na seção "Cara a Cara" é retomada tal questão em: "Que alguém sempre paga a conta dos bens e serviços públicos que eu (alunos) utilizo gratuitamente". Porém, em outro trecho do material o governo reforça que todos os serviços dos quais o cidadão usufrui vêm dos tributos pagos por estes, como "para promover a igualdade e garantir certo nível de bem-estar social, o governo mantém serviços de saúde e educação públicos, dentre outros, mantidos com os tributos (impostos, taxas e contribuições de melhorias) que todos nós pagamos" (CONEF, 2013, p. 14).

Em outro trecho, há dicassobre como não onerar o estado, por exemplo, "tomar cuidados com sua higiene e saúde, para não gerar gastos com doenças que poderiam ter sido evitadas" (CONEF, 2013, p. 42). Mais uma vez, os autores utilizam-se de uma linguagem moldada, para dar ao cidadão o "poder do conhecimento" para que eles mesmos se responsabilizem por seu bem-estar, ou dito de outro modo, para que haja menos necessidade de consultas e/ou de medicamentos fornecidos pelo Estado.

Considerando a composição do CONEF e COREMEC e seus interesses nas questões econômicas e de consumo de serviços e produtos complexos relacionados à esfera financeira, o material apresenta conteúdos intimamente ligados a serviços, os quais o jovem deve saber para investir, poupar e consumir de forma "consciente", fatos que se comprovam nas contradições no que tange ao consumo consciente, à tomada de decisões autônomas, enfim,à presença de técnicas neoliberais de governamentalidade.

\section{Algumas considerações}

A análise do Livro do Aluno Bloco 3 Ensino Médioevidenciou o quanto o tema educação financeira é relevante tanto para a vida pessoal quanto social do indivíduo e também nos mostrou a importância de conhecer e entender profundamente os programas propostos pelo Governo.

Por meio da pesquisa bibliográfica e leitura do material escolhido para este artigo, identificaramsecontradições que podem colocar em dúvida a real intenção do Programa, como quando comparamos o objetivo do programa, que é "contribuir para o desenvolvimento da cultura de planejamento, prevenção, poupança, investimento e consumo consciente" (AEF-BRASIL, 2017), com dois objetivos das dimensões espacial e temporal, que serviram como base para elaboração do conteúdo de educação financeira.

O objetivo 3 da dimensão espacial, propõe que, por meio das ferramentas e conceitos oferecidos pelo material, os indivíduos terão maior "autonomia na tomada de decisão", tornando-se donos do seu destino, e não mais "beneficiários passivos de programas econômicos e sociais" (COREMEC, 2009, p.12). Este pontovem de encontro a outros mencionados no decorrer deste trabalho, como trechos contraditórios sobre a gratuidade dos serviços públicos, o pagamento de tributos ea opção de financiamento como única forma de conseguir dinheiro para abrir um negócio, sem a apresentação de outros meios.

Já oobjetivo 2 da dimensão temporal discorre sobre a cultura da prevenção, o quanto é importante conhecer as opções disponíveis para poupar e prevenir imprevistos, "como evitar desperdícios, guardar dinheiro, fazer seguros diversos ou investimentos ou dispor de planos de previdência (pública ou privada) (COREMEC, 2009, p. 
13).Porém,estas opções disponíveisnão foram apresentadas no Livro nos momentos propostos de reflexão, como no trecho "Pergunte ao especialista"e "Cara a Cara", o que não significa, que nos demais livros Bloco 1 e 2 - Ensino Médio, não tenhamsido ressaltados estes momentos de reflexão.

Com base nas análises e no conceito de governamentalidade, o material apresenta-se como uma técnica bem elaborada para influenciar a "consciência" e "autonomia" do jovem aluno, sobre o que, como e onde ele pode poupar e investir para aumentar sua satisfação pessoal, em especial, via consumo. Os textos reforçam a importância do conhecimento em educação financeira para sair de endividamentos, mas também induzem aconsumir mais por outros meios, ou seja, a "não se endividar para consumir mais" (BUARQUE, 2012 apud FELICIANO, 2012, p. 57). Além disso, enfatizam níveis adequados de consumo para uma melhor economia, mas não evidenciam quem e como considera este nível adequado, ou seja, deixa nebuloso o limite entre saudável e maléfico no que tange ao consumo.

Em relação à responsabilidade individual do aluno, o programa, ao menos o Bloco 3, atua como o fomentador do "ser protagonista da própria vida", mas, ao mesmo tempo,não expande a educação financeira para além do âmbito social definido pelos autores, como reforçando a importância da liberdade de escolha:emprestar dinheiro de um amigo ou parente para não pagar juros em vez de um financiamento no banco; guardar dinheiro para realizar um objetivo em vez de um empréstimo; fazer compras com dinheiro em vez de com cheque e/ou cartão,são algumas das opções de ação não mencionadas.

Entende-se que há contradição no material analisado no que tange ao ensino do consumo consciente e que as ações propostas pelo Programa Transversal da ENEF, que "perpassam vários setores e transcendem os interesses de uma instituição específica" (CONEF, 2014), de fato, são notadas quando se explora, sob a luz do conceito de governamentalidade, o real sentido da interface do programa com os autores envolvidos e o material desenvolvido. Enfim, a desconstrução do Livro do Aluno, Bloco 3 - Ensino Médio, apresentada neste trabalho, teve como pretensão desvendar, de forma sucinta, a finalidade do programa e o material analisados, de forma a colaborar para "governarmos a nós mesmos e aos outros exercendo nosso pensamento sobre o que consideramos verdadeiro." (FIMYAR, 2009, p. 41).

\section{Notas}

1 Artigo apresentado por Noelle Cristina Alves Cabral como parte dos requisitos para obtenção do Diploma de Bacharelado em Administração na Fundação Universitária Vida Cristã - Faculdade de Pindamonhangaba, em novembro de 2017, sob a orientação da Profa. Ma. Luciana Aparecida Silva de Azeredo e coorientação do Prof. Dr. Guilherme Muniz Pereira Chaves Urias.

2 Leu-se uma resenha em português, não publicada, e elaborada por Profa. Ma Luciana Ap. S. de Azeredo.

\section{Referências}

ABREU, R. J. R. Educação Financeira: Aspectos discursivos, subjetivação e governamentalidade. 2015. Inserir total de páginas. Dissertação (Mestrado em Educação) - Universidade São Francisco, Itatiba, 2015.

\section{AEF-BRASIL: ASSOCIAÇÃO DE EDUCAÇÃO} FINANCEIRA DO BRASIL. Tecnologias Sociais e Educacionais. Brasil, jun. 2017. Disponível em: $<$ http://www.aefbrasil.org.br/index.php/tecnologiassociais-e-educacionais/>. Acesso em: 26 jun. 2017.

\section{AEF-BRASIL: ASSOCIAÇÃO DE EDUCAÇÃO FINANCEIRA DO BRASIL.Programas}

Transversais. Brasil, jul. 2017. Disponível em: <www.vidaedinheiro.gov.br>. Acesso em: 03 jul. 2017.

BANCO CENTRAL DO BRASIL: DEPARTAMENTO DE EDUCAÇÃO FINANCEIRA DO BANCO CENTRAL DO BRASIL. Brasil: Implementando a estratégia nacional de educação financeira. Brasil, 2012. Disponível em:

$<$ https://www.bcb.gov.br/pre/pef/port/Estrategia_Na cional_Educacao_Financeira_ENEF.pdf $>$. Acesso em: 26 jun. 2017.

BANCO CENTRAL DO BRASIL. Gestão de Finanças Pessoais. Caderno de educação financeira, Brasília, 2013.

BAUMAN, Z. Vida a crédito: conversas com Citlali Rovirosa-Madrazo. Rio de Janeiro: Zahar, 2010. 
BM\&FBOVESPA. Resultados da avaliação de impacto do projeto piloto de educação financeira nas escolas. Brasil, jun. 2012. Disponível em: $<$ http://www.aefbrasil.org.br/wpcontent/uploads/Release_BMFBOVESPA.pdf >. Acesso em: 27 jun. 2017.

BRASIL. Congresso. Decreto n. ${ }^{\circ}$ 7.397, de 22 de dezembro de 2010.Institui a Estratégia Nacional de Educação Financeira - ENEF, dispõe sobre a sua gestão e dá outras providências. Disponível em: <http://www.planalto.gov.br/ccivil_03/_Ato20072010/2010/Decreto/D7397.htm>. Acesso em: 10 jun. 2017.

CALIFE, F.; COSENZA, F. A história não contada da educação financeira no Brasil. Boa Vista

Serviços, 2014. Disponível em:

<http://www.boavistaservicos.com.br/wpcontent/uploads/2014/08/A-história-não-contada-daeducação-financeira-no-Brasil.pdf>. Acesso em: 26 jun. 2017.

CONEF: Comitê Nacional de Educação Financeira. Educação Financeira nas escolas: ensino médio. 1.ed. Brasília: DF. CONEF, 2013.

CONEF: COMITÊ NACIONAL DE EDUCAÇÃO FINANCEIRA. Infografo. 2014. Disponível em: <http://www.vidaedinheiro.gov.br/imagem/Infografi co-ENEF-0508.pdf>. Acesso em: 29 jun. 2017.

COREMEC. Orientação para educação financeira nas escolas. Brasil, 2009. Disponível em: <http://www.vidaedinheiro.gov.br/wpcontent/uploads/2017/08/DOCUMENTO-ENEFOrientacoes-para-Educ-Financeira-nasEscolas.pdf>. Acesso em: 21 jun. 2017.

ENEF: ESTRATÉGIA NACIONAL DE EDUCAÇÃO FINANCEIRA. Educação Financeira: no Brasil. Brasil, jun. 2017. Disponível em: <http://www.vidaedinheiro.gov.br/pagina-23no-brasil.html>. Acesso em: 26 jun. 2017.

ENEF: ESTRATÉGIA NACIONAL DE EDUCAÇÃO FINANCEIRA. Implementando a estratégia nacional de educação financeira. Brasil, 2009. Disponível em:

<https://www.bcb.gov.br/pre/pef/port/Estrategia_Na cional_Educacao_Financeira_ENEF.pdf.> Acesso em: 03 jul. 2017.
FECOMERCIO. Pesquisa de Endividamento e Inadimplência do Consumidor - PEIC. Série Histórica, 2017. Disponível em:

<http://www.fecomercio.com.br/pesquisas/indice/pe ic>. Acesso em: 09 nov. 2017.

FELICIANO, J. V. "Direito a Felicidade" Uma visão da PEC 19/2010. 2012. Monografia (Bacharelado em Direito), Faculdade Anhanguera, Jacareí, 2012.

FERNANDES, L. F. B.; VILELA, D. S. A constituição da educação financeira no Brasil neoliberal. Anais VIII Seminário de dissertações e teses, São Carlos, 9 f., 2016. Disponível em: <http://www.ppge.ufscar.br/wpcontent/uploads/2016/10/Anais-VIII-Seminário-deDissertações-e-Teses.pdf> . Acesso em: 20 jul. 2017.

FIMYAR, O. Governamentalidade como ferramenta conceitual na pesquisa de políticas educacionais. Inserir edição. Educação e Realidade, Rio Grande do Sul, ago. 2009.

GORDON, C. Governmental Rationality: An Introduction. In: BURCHELL, G.; GORDON, C. and MILLER, P (Org.). The Foucault Effect: Studies in Governmentality. Hemel Hempstead: Harvester Wheatsheaf, 1991.

ITAMARATY. OCDE: Organização para a cooperação e o desenvolvimento econômico. 201617. Disponível em: $<$ http://www.itamaraty.gov.br/ptBR/component/tags/tag/15-ocde-organizacao-paraa-cooperacao-e-o-desenvolvimento-economico>. Acesso em: 05 jul. 2017.

KASTNER, T. Mercado: Consumidor tenta ir às compras, mas esbarra em crédito negado. Folha Digital, São Paulo, publicação 17 jul. 2017.

Disponível em <

http://www1.folha.uol.com.br/mercado/2017/07/190 1765-consumidor-tenta-ir-as-compras-mas-esbarraem-credito-negado.shtml>. Acesso em: 18 jul. 2017.

MARTINS, D.; RAGAZZI, A. P. Especialista defende educação financeira para reduzir desigualdade. Valor Econômico, Rio de Janeiro, 2014. Disponível em: <http://www.valor.com.br/brasil/3720494/especialis ta-defende-educacao-financeira-para-reduzirdesigualdade>. Acesso em: 17 jul. 2017. 
MENDES, M. Por que o governo deve interferir na economia. Brasil Economia e Governo, 2011.

Disponível em: <http://www.brasil-economiagoverno.org.br/wp-content/uploads/2011/03/porque-o-governo-deve-interferir-na-economia.pdf $>$. Acesso em: 10 jul. 2017.

MORA, M. A evolução do crédito no Brasil entre 2003 e 2010. Rio de Janeiro: IPEA - Instituto de Pesquisa Econômica Aplicada, 2015.

OCDE.Estratégias nacionais para a educação financeira. Brasil, 2017. Disponível em: <http://www.oecd.org/daf/fin/financialeducation/nationalstrategiesforfinancialeducation.ht m>. Acesso em: 29 jun. 2017.

OLIVEIRA, C. Lusardi, da George Washington: o poder da poupança. Exame.com, São Paulo, 2017. Disponível em:

$<$ http://exame.abril.com.br/negocios/lusardi-degeorgetown-o-poder-do-cofrinho/>. Acesso em: jul. 2017.

PORTAL BRASIL. Reforma da previdência: As próximas gerações de brasileiros merecem ter Previdência. Brasil, 2016. Disponível em: $<$ http://reformadaprevidencia.gov.br/noticias/as- proximas-geracoes-de-brasileiros-merecem-terprevidencia.html>. Acesso em: 06 jul. 2017.

PARÂMETROS CURRICULARES NACIONAIS. PONTO DE CONTATO NACIONAL DAS DIRETRIZES DA OCDE. Conheça os trabalhos da Organização para Cooperação e Desenvolvimento Econômico. Brasil, jul. 2017. Disponível em: $<$ http://www.pcn.fazenda.gov.br/assuntos/ocde/sobr e-a-ocde>. Acesso em: 03 jul. 2017.

REVEL, J. Michel Foucault: conceitos essenciais. Inserir edição. São Carlos: Editora Claraluz, 2005.

SERASA EXPERIAN. Número de inadimplentes bate recorde histórico ao atingir 61 milhões. Brasil: SerasaConsumidor, 2017. Disponível em: <http://noticias.serasaexperian.com.br/blog/2017/07 /03/numero-de-inadimplentes-bate-recordehistorico-ao-atingir-61-milhoes/>. Acesso em: 07 jul. 2017.

SPC-BRASIL. Pesquisa educação financeira: Orçamento Pessoal e Conhecimentos Financeiros. Brasil, 2015. Disponível em: $<$ https://www.spcbrasil.org.br/uploads/st_imprensa/ analise_educacao_financeira_20151.pdf $>$. Acesso em: 10 jul. 2017.

\section{Sobre os autores}

Noelle Cristina Alves Cabral é bacharel em Administração e atua no setor de Logística da multinacional alemã BASF S.A, tendo atuado também na área de Recursos Humanos.

Luciana Aparecida Silva de Azeredo é licenciada em Letras Português-Inglês, Mestre em Linguística Aplicada e doutoranda em Educação. É professora efetiva no Centro Federal de Educação Tecnológica de Minas Gerais (CEFET-MG), atuando no Campus I, em Belo Horizonte. Atualmente, desenvolve pesquisas a respeito do cuidado de si foucaultiano e o ensino e aprendizagem de línguas estrangeiras, em especial sobre a Teoria da Complexidade e a Pedagogia dos Multiletramentos.

Guilherme Muniz Pereira Chaves Urias é licenciado em Física, Mestre e Doutor em Educação para a Ciência. Professor da Secretaria Estadual de Educação em Minas Gerais, atuando na escola estadual Major Lisboa da Cunha, em Wenceslau Braz. Desenvolve pesquisas para a criação e aplicação de atividades pedagógicas nas aulas de Física na Educação Básica e no Ensino Superior, baseadas nas metodologias ativas de ensino, tais como Blended Learning, Problem Based Learning, Peer Instruction, entre outras.

Recebido em janeiro de 2018.

Aprovado em abril de 2018. 